3. Mã Tú Thañh, Phạm Văn Quang (2017) "Đặc điểm dich tễ, lâm sàng, cân lầm sàng ở bênh nhi bị rắn lục tre cắn tại Bệnh viện Nhi Đồng 1 ". Tạp chí Y học TP. Hồ Chí Minh, 21 (4), tr.252-259.

4. Arnuparp Lekhakula (2014) "Management of Malayan Pit Viper Bites". Journal of Hematology and Transfusion Medicine, 24, 163-73.

5. Soumyadeep Bhaumik, Soushieta Jagadesh, Zohra Lassi (2018) "Quality of WHO guidelines on snakebite: the neglect continues". BMJ global health, 3 (2), e000783-e000783.
6. Kanthika Kraisawat, Nattaya Promwang (2020) "Duration after Malayan Pit Viper Bite to Detect Coagulopathy in Songklanagarind Hospital". Journal of Health Science and Medical Research, 38, 93-101.

7. Cheng $H$. Toh, Yasir Alhamdi, Simon $T$. Abrams (2016) "Current Pathological and Laboratory Considerations in the Diagnosis of Disseminated Intravascular Coagulation". Annals of laboratory medicine, 36 (6), 505-512.

\title{
ĐÁNH GIÁ THỜI GIAN SỐNG THÊM UNG THƯ DA DÀY Ở NGƯờI CAO TUỔI SAU PHẪU THUÂ̂T PHỐI HỢP HÓA CHẤT PHÁC ĐỒ EOX
}

\section{TÓM TẮT}

Mục tiêu: Đánh giá thời gian sống thêm của ung thư da dày ở người cao tuổi sau phẫu thuât phối hợp hóa chất phác đồ EOX. Phương pháp nghiên cứu: Nghiên cứu can thiệp lâm sàng không đối chứng có theo dõi dọc, kết hợp tiến cứu và hồi cứu. Gồm 57 bệnh nhân là người cao tuổi được chẩn đoán xác định là ung thư dạ dày giai đoạn IIa-İIIc được điều trị phẫu thuật tai bệnh viện $K$ và bệnh viện $E$ từ tháng $1 / 2009$ đến tháng 12/2019. Kết quả Thời gian sống thêm toàn bộ chung của nhóm nghiên cứu 3 năm là $85,6 \%$, 4 năm là $59,7 \%, 5$ năm là $46,7 \%$. Thời gian sống thêm toàn bộ trung bình là 49,7 $\pm 1,8$ tháng. Thời gian sống thêm không bệnh tích lũy 3 năm là $63,5 \%, 4$ năm là $45,8 \%, 5$ năm là $35,6 \%$. Thời gian sống thêm không bệnh trung bình là 44,4 $\pm 2,1$ tháng. Bệnh nhân có bệnh tim mạch kèm theo có thời gian sống thêm trung bình là $37,45 \pm 3,5$ tháng thấp hơn so với thời gian sống thêm trung bình của nhóm không có bênh tim mach kèm theo $(51,8 \pm 1,8$ tháng). Kết luân: Hóa trị bổ trợ phác đồ EOX đem lại lợi ích sống thềm trên bệnh nhân cao tuổi ung thư da dày đã phấu thuật triệt căn có nguy cơ cao.

Tư khóa: Ung thư da dày; phác đồ EOX; thời gian sống thêm, người cao tuổi.

\section{SUMMARY \\ EVALUATION ON SURVIVAL TIME AFTER SURGERY AND EOX REGIMEN CHEMOTHERAPY TO TREAT GASTRIC CANCER IN ELDERLY PATIENTS}

Objectives: to evaluate the survival time after surgery and EOX regimen chemotherapy to treat gastric cancer in elderly patients. Subjects and methods: Non-controlled clinical interventional study

\section{${ }^{1}$ Bênhh viện $E$}

Chiu trách nhiệm chính: Lê Thành Trung

Email: bslethanhtrung@yahoo.com

Ngày nhận bài: 15.3.2021

Ngày phản biên khoa học: 12.5 .2021

Ngày duyệt bài: 19.5.2021

\section{Lê Thành Trung ${ }^{1}$, Đoàn Hữu Nghị ${ }^{1}$}

with vertical follow-up, with a combination of prospective and retrospective study was conducted on 57 elderly patients diagnosed with gastric cancer staged IIa - IIIc and undergoing surgical treatment at K Hospital and E hospital from January, 2009 to December, 2019. Results: Overall survival rate of the study groups of 3 years was $85.6 \%$, of 4 years was $59.7 \%$, of 5 years was $46.7 \%$. The mean overall survival time was $49.7 \pm 1.8$ months. The disease-free survival rate of 3 years was $63.5 \%$, 4 years was $45.8 \%, 5$ years was $35.6 \%$. The mean disease-free survival time was $44.4 \pm 2.1$ months. Patients with comorbid conditions of cardiovascular disease had a median survival time of $37.45 \pm 3.5$ months, which was lower than the mean survival time of the group without comorbid conditions of cardiovascular disease (51.8 $\pm 1,51.8 \pm 1.8$ months). Conclusions: Adjuvant chemotherapy EOX regimen improved survival time in patients with gastric cancer after radical surgeries.

Keywords: gatric cancer, EOX regimen, survival time, elderly.

\section{I. ĐẶT VẤN ĐỀ}

Tại Việt nam theo Globocan 2018, UTDD đứng thứ 3 ở cả hai giới sau ung thư gan và ung thư phổi với tỷ lệ mắc chuẩn theo tuổi là 11,38/100.000 dân. Trong đó, loại ung thư biểu mô tuyến chiếm chủ yếu (90-95\%) [1].

Trong điều trị ung thư dạ dày, phẫu thuật được xem là phương pháp điêuu trị chính. Các nghiên cứu ở nước ta cho thấy đa số bệnh nhân được chẩn đoán ở giai đoạn bệnh tiến triển, thường xuất hiện tái phát, di cằn sau khi đã được phẫu thuật [2]. Mặc dù kỹ thuật phẫu thuật ung thư dạ dày ngày càng tiến bộ, nhưng kết quả sống thêm toàn bộ của bệnh nhân ung thư da dày giai đoạn tiến triển vẩn thấp, tỷ lể sống 5 năm chỉ đạt 25-45\% [3], [4]. Chính vì vậy, để cải thiện tiên lượng của ung thư dạ dày giai đoạn tiến triển, ngoài hoàn thiện phương pháp phẫu thuật điều trị triệt căn cổ điển, hiện 
nay các nghiên cứu tập trung điều trị đa mô thức như phẫu thuật kết hợp hóa chất, hóa-xạ phối hợp, miễn dịch-sinh học... đặc biệt phương pháp điều trị hóa trị toàn thân là rất cần thiết.

ở Việt Nam và trên thế giới đã có một số nghiên cứu đánh giá kết quả điều trị và tác dụng không mong muốn của phác đồ EOX trong điều trị ung thư dạ dày sau phẫu thuật triệt căn, tuy nhiên chưa có nhiều nghiên cứu thực hiện trên đối tượng là người cao tuổi, đặc biệt là về đánh giá kết quả điều trị, thời gian sống thêm.

Vì vậy, chúng tôi tiến hành nghiên cứu này với mục đích: Đánh giá thời gian sống thêm của ung thư da dày ở người cao tuổi sau phẫu thuật phối hợp hóa chất phác đồ EOX.

\section{II. ĐỐI TƯỢNG VÀ PHƯƠNG PHÁP NGHIÊN CỨU}

Nghiên cứu can thiệp lâm sàng không đối chứng có theo dõi dọc, kết hợp tiến cứu và hồi cứu.

Đối tượng nghiên cứu. Từ tháng 1/2009 đến tháng 12/2019, chúng tôi tiến hành nghiên cứu trên 57 bệnh nhân (là người cao tuổi: từ 60 tuổi trở lên theo định nghĩa của WHO và Pháp lệnh về người cao tuổi của ủy ban thường vụ quốc hội nước $\mathrm{CHXHCN}$ Việt Nam, Số 23/2000/PL-UBTVQH10 ngày 28/4/2000) được chẩn đoán xác định là ung thư da dày giai đoạn IIa-IIIc được điều trị phầu thuật và hóa chất phác đồ $E O X$ tại Bệnh viện $K$ và bệnh viện $E$.

Tiêu chuẩn lựa chọn: Bệnh nhân được chẩn đoán xác định là ung thư dạ dày giai đoạn IIa-IIIc. Mô bệnh học loai ung thư biểu mô; Tuổi $\geq 60$; Được điều trị phẩu thuật cắt dạ dày triệt căn; Được điều trị hóa chất phác đồ EOX; Hồ sơ lưu trữ đầy đủ; Đồng ý tham gia nghiên cứu

Tiêu chuẩn loại trừ: Thể trạng yễu; Đã được hóa xạ trị trước mổ hoặc phẫu thuật không đảm bảo triệt căn; Các trường hợp đã mắc một bệnh ung thư khác

Tiến hành nghiên cứu: những bệnh nhân có đủ các tiêu chuẩn sẽ được chọn vào nghiên cứu. Thông tin của các bệnh nhần nghiên cứu được thu thập và ghi nhận theo mẫu bệnh án nghiên cứu.

\section{Các tiêu chuẩn đánh giá}

- Đánh giá TNM, giai đoạn bệnh theo AJCC 2017.

- Đánh giá thời gian sổng thêm:

+ Thời điểm bắt đầu chọn bệnh nhân vào nghiên cứu: tính từ ngày bắt đầu tiến hành điều trị bệnh nhân. Thông tin về tình trạng bệnh nhân sau điều trị thu thập qua những lần khám lại hoặc qua điện thoại.

+ Thời điểm kết thúc nghiên cứu

o Bệnh nhân được theo dõi đủ 05 năm
○ Ngày tử vong trước thời điểm kết thúc nghiên cứu quy ước.

○ Ngày mất theo dõi: ngày khám bệnh cuối cùng còn sống, sau đó không có thông tin nào khác (sự kiện mất theo dõi này xảy ra trước thời điểm kết thúc nghiên cứu quy ước).

- Tái phát sau điều trị: Chẩn đoán tái phát qua khám lâm sàng, chẩn đoán hình ảnh, xét nghiệm tế bào và mô bệnh học.

- Di căn sau điều trị: các tổn thương di căn xa xuất hiện sau điều trị, chẩn đoán di căn dựa vào khám lâm sàng, chẩn đoán hình ảnh, xét nghiệm tế bào và mô bệnh học.

- Những trường hợp không khám lại dựa trên chẩn đoán của y tế cở sở thời điểm xuất hiện tái phát, di căn.

- Thời gian sống thêm: là khoảng thời gian giữa thời điểm bắt đầu vào nghiên cứu và thời điểm kết thúc (rút khỏi) nghiên cứu.

- Tình trang người bệnh: sống hay chết; khoẻ mạnh hay tái phát - di căn.

- Sự kiện nghiên cứu là sự kiện chết đối với các tính toán sống thêm toàn bộ và sự kiện tiến triển, tái phát - di căn.

- Thời gian sống thêm toàn bộ: tính từ thời điểm bắt đầu can thiệp điều trị đến khi bệnh nhân tử vong hoặc có thông tin cuối cùng.

- Thời gian sống thêm không bệnh: tính từ khi bắt đầu điều trị đễn khi bệnh có dấu hiệu tái phát, di căn trên lầm sàng, chẩn đoán hình ảnh và chỉ điểm $u$.

\section{KẾT QUẢ NGHIÊN CỨU}

Thông tin chung. Nam giới chiếm tỉ lệ $75,4 \%$, nữ là $24,6 \%$, tỉ lệ xấp xỉ $3 / 1$.

Nhóm tuổi $\leq 65$ chiếm đa số $(77,2 \%)$, nhóm tuổi trên 65 chiếm 22,8\%.

Có 22 bệnh nhân $(38,6 \%)$ có kích thước u dưới $3 \mathrm{~cm}, 35$ bệnh nhân có kích thước u trên $3 \mathrm{~cm}(61,4 \%)$.

Giai đoạn bệnh: IIA (21,2\%), IIB (33,3\%), IIIA $(31,6 \%)$, IIIB (7\%), IIIC (7\%).

Bảng 1. Bệnh kèm theo của nhóm nghiên cứu ( $n=57)$

\begin{tabular}{|c|c|c|c|}
\hline \multicolumn{2}{|c|}{ Bệnh kèm theo } & $\begin{array}{c}\text { Số } \\
\text { Iượng }\end{array}$ & $\begin{array}{c}\text { Tỉ lệ } \\
\text { \%o }\end{array}$ \\
\hline \multirow{2}{*}{$\begin{array}{c}\text { Tim } \\
\text { mạch }\end{array}$} & Tăng huyết áp & 9 & 15,8 \\
\cline { 2 - 4 } & Block nhĩ thất & 2 & 3,6 \\
\hline Cơ xương & Viêm khớp, thấp khớp & 4 & 7,0 \\
\cline { 2 - 4 } khớp & Đau lưng mãn tính & 5 & 8,8 \\
\hline \multicolumn{2}{|c|}{ Bệnh thận hoặc đường tiết niệu } & 7 & 12,3 \\
\hline \multirow{2}{*}{ Khác } & Đái tháo đường & 6 & 10,5 \\
\cline { 2 - 4 } & Viêm gan B & 1 & 1,8 \\
\hline
\end{tabular}




\begin{tabular}{|c|c|c|c|}
\hline & Xuất huyết tiêu hóa & 1 & 1,8 \\
\cline { 2 - 4 } & Viêm loét dạ dày & 7 & 12,3 \\
\hline
\end{tabular}

Nhận xét: Bệnh nhân chủ yếu có bệnh kèm theo là tăng huyết áp $(15,8 \%)$, viêm loét da dày $(12,3 \%)$, bệnh thận hoặc đường tiết niệu $(12,3 \%)$, đái tháo đường $(10,5 \%)$.

\section{Thời gian sống thêm toàn bộ}

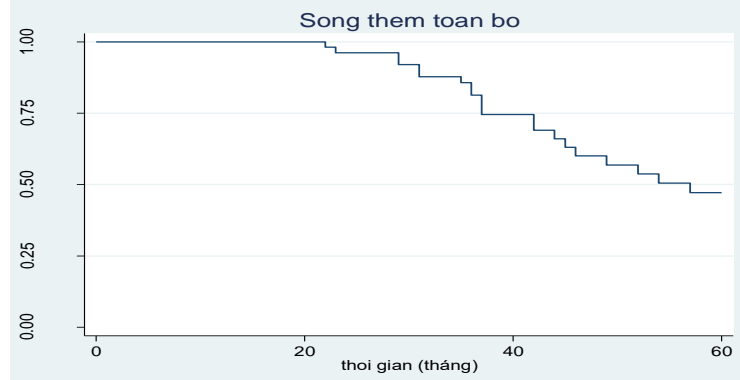

Biêu đồ 3. 1. Biểu đồ Kaplan - Meier mô tả thời gian sống thêm toàn bô $(n=57)$

Nhận xét: Thời gian sống thêm toàn bộ

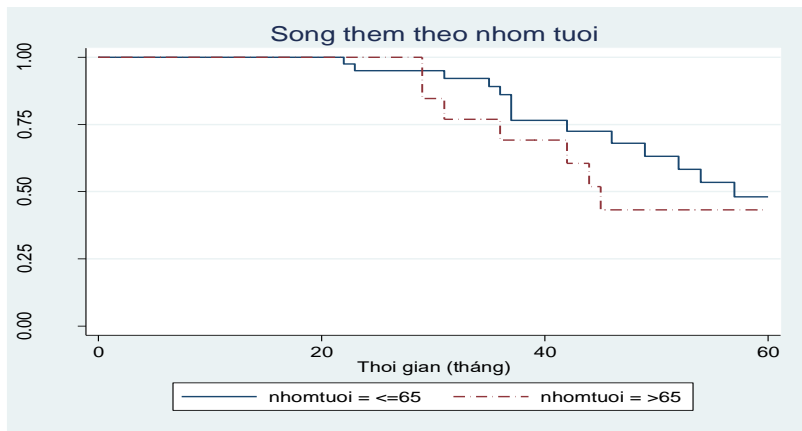

$p=0,4996$ chung của nhóm nghiên cứu 3 năm là $85,6 \%, 4$ năm là 59,7\%, 5 năm là 46,7\%. Thời gian sống thêm toàn bộ trung bình là $49,7 \pm 1,8$ tháng.

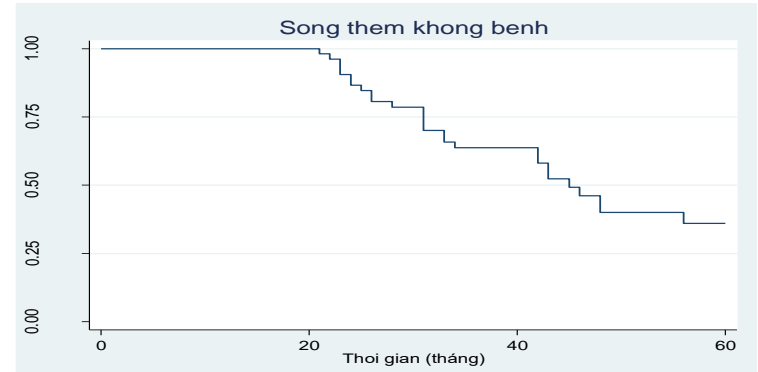

Biểu đồ 3. 2. Biểu đồ Kaplan - Meier mô tả thời gian sống thêm không bệnh $(n=57)$

Nhận xét: Thời gian sống thêm không bệnh tích lũy 3 năm là $63,5 \%, 4$ năm là $45,8 \%, 5$ năm là $35,6 \%$. Thời gian sống thêm không bệnh trung bình là $44,4 \pm 2,1$ tháng.

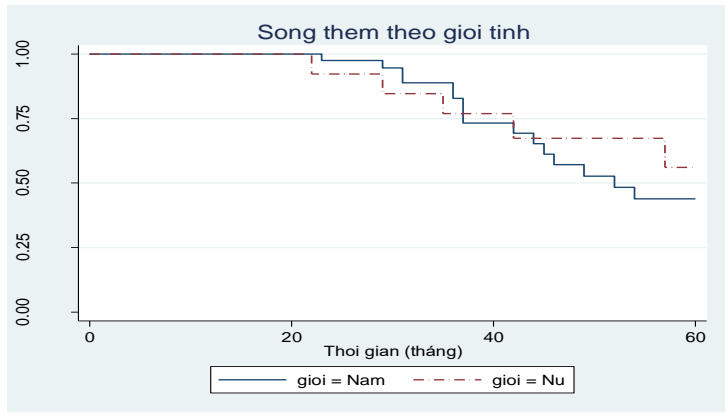

$p=0,6491$

Biểu đồ 3.3. Biểu đồ Kaplan - Meier mô tả liên quan thời gian sống thêm

theo nhóm tuối và giới tính $(n=57)$

Nhận xét: Không có mối liên quan giữa thời gian sống thêm với nhóm tuổi và giới tính.

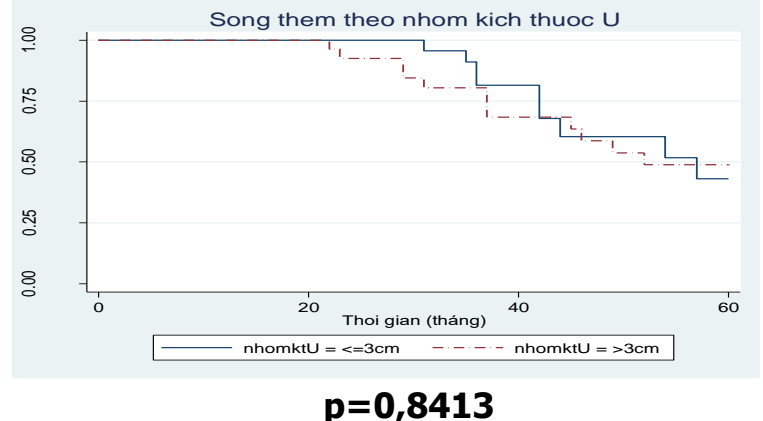

Biểu đồ 3.4. Biêu đồ Kaplan - Meier mô tả liên quan thời gian sống thêm với kích thước khôi u $(n=57)$

Nhân xét: Nhóm BN có kích thước $\mathrm{u} \geq 3 \mathrm{~cm}$ có thời gian sống thêm ngắn hơn so với nhóm có kích thước $\mathrm{u}<3 \mathrm{~cm}$. Tuy nhiên sự khác biệt chưa có ý nghĩa thống kê với p>0,05.

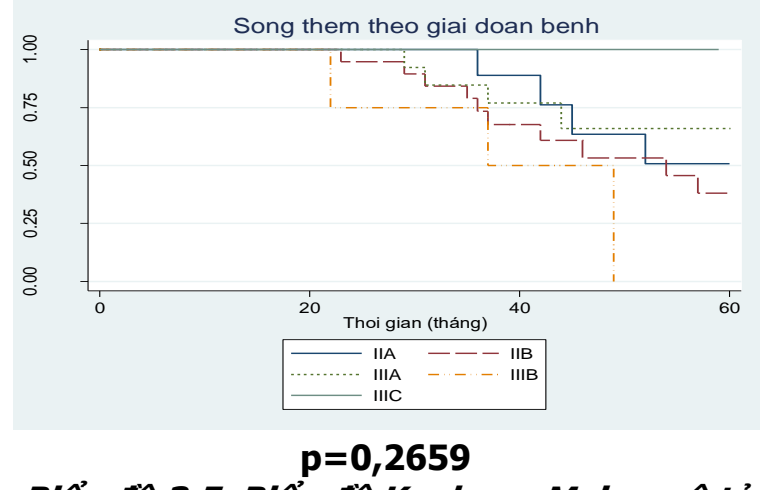

Biểu đồ 3.5. Biểu đồ Kaplan - Meier mô tả liên quan thời gian sống thêm với giai đoạn bệnh $(n=57)$

Nhân xét: Chưa thấy mối liên quan giữa thời gian sống thêm và giai đoạn bệnh $(p>0,05)$ 


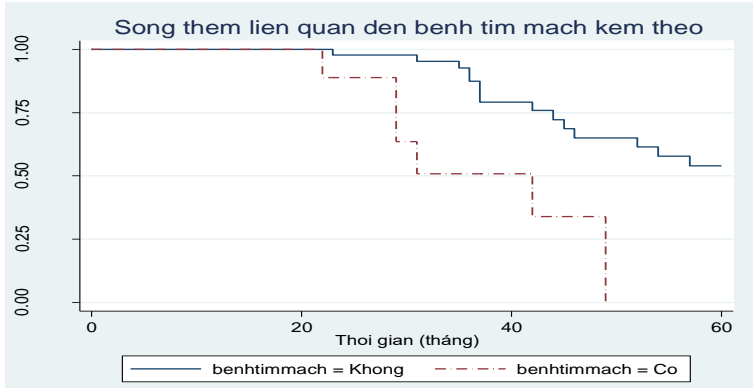

$\mathbf{p}=0,003$

Biểu đồ 3.6. Biểu đồ Kaplan - Meier mô tả liên quan thời gian sống thêm với bệnh tim mach kèm theo $(n=57)$

Nhận xét: Bệnh nhân có bệnh tim mạch kèm theo có thời gian sống thêm trung bình là $37,45 \pm 3,5$ tháng thấp hơn so với thời gian sông thêm trung bình của nhóm không có bệnh tim mach kèm theo ( $51,8 \pm 1,8$ tháng). Sự khác biệt có ý nghĩa thống kê với $p<0,05$

\section{BÀN LUÂ̂N}

Đắc điểm của bệnh nhân. Nghiên cứu của chúng tôi thực hiện trên 57 bệnh nhân UTDD giai đoạn IIA-IIIC có u xâm lấn tới thanh mạc hoặc cấu trúc lân cận (T4a và T4b) thuộc nhóm có tỷ lệ gặp cao trong điều kiện Việt Nam. Các bệnh nhân sau khi được phẫu thuật cắt dạ dày triệt căn có đủ điều kiện được hóa trị bổ trợ phác đồ EOX liệu trình 6 chu kỳ.

Kết quả nghiên cứu cho thây: đa số bệnh nhân trong nghiên cứu là nam chiếm tỉ lệ $75,4 \%$, nữ là 24,6\%, tỉ lệ xấp xỉ 3/1. Nhóm tuổi $\leq 65$ chiếm đa số $(77,2 \%)$, nhóm tuổi trên 65 chiếm $22,8 \%$. Có 22 bệnh nhân $(38,6 \%)$ có kích thước u dưới $3 \mathrm{~cm}, 35$ bệnh nhân có kích thước u trên $3 \mathrm{~cm}(61,4 \%)$. Giai đoạn bệnh: IIA (21,2\%), IIB $(33,3 \%)$, IIIA $(31,6 \%)$, IIIB (7\%), IIIC (7\%). Bệnh kèm theo chủ yếu là tăng huyết áp $(15,8 \%)$, viêm loét dạ dày $(12,3 \%)$, bệnh thận hoăcc đường tiết niệu $(12,3 \%)$, đái tháo đường $(10,5 \%)$.

Thời gian sống thêm. Thời gian theo dõi bệnh nhân sau điêuu trị từ 14 tháng đến 60 tháng, trung bình 41 tháng. Số bệnh nhân còn sống là 36, có 21 bệnh nhân đã tử vong, số Thời gian sống thêm toàn bộ trung bình là 49,7 $\pm 1,8$ tháng, sống thêm không bệnh trung bình là 44,4 $\pm 2,1$ tháng. Tỷ lệ sông thêm toàn bộ ước tính theo Kaplan - Meier sau 3 năm, 4 năm và 5 năm tương ứng là $85,6 \%, 59,7 \%, 46,7 \%$. Tỷ lệ sống thêm không bệnh sau 3 năm, 4 năm và 5 năm ước tính tương ứng là $63,5 \%, 45,8 \%$ và $35,6 \%$.

So với các tác giả khác như Bang (2012) tỉ lệ sống thêm toàn bộ sau 3 năm ở nhóm điêu trị bổ trợ là $83 \%$ còn nhóm phẫu thuật đơn thuân đat $78 \%$. Tỷ lê sống thêm 3 năm không bênh ở nhóm điều trị bổ trợ là $74 \%$ và nhóm phẫu thuât đơn thuân chì là 59\% [5]. Phan Cảnh Duy nghiên cứu trên 54 bệnh nhân ung thư biểu mô tuyến phân xa dạ dày giai đoạn tiến triển tại chỗ được điều tri bằng phẩu thuất kết hợp xa - hóa sau mổ, tỷ lệ sống thêm toàn bộ sau 1,3 và 5 năm lân lượt là $94,4 \%, 58,4 \%$ và $26,5 \%$ [3]. Vũ Quang Toản nghiên cứu 152 trường hợp bệnh nhân UTDD giai đoạn IIB-III (T4, NO-3, MO) được hóa trị bổ trợ phác đồ EOX sau phẫu thuật triệt căn, tỷ lệ sống thêm toàn bộ sau 3 năm, 4 năm và 5 năm ước tính tương ứng là $61,8 \%$; $50,7 \%$ và $48,1 \%$.

Như vậy, so sánh với các tác giả khác thì các bệnh nhân trong nhóm nghiên cứu bệnh đã tiến triển tại chỗ, u đã xâm lấn tới thanh mạc hoặc cấu trúc lân cân (T4a và T4b) được điêuu trị bổ trợ bằng phác đồ hóa trị EOX gồm 3 thuốc đã có sự cải thiện tỷ lệ sống thêm đáng khích lệ. Các nghiên cứu về hóa trị bổ trợ cũng chưa có tác giả nào đặt vấn đề với nhóm những bệnh nhân người cao tuổi có nguy cơ tái phát, di căn cao chiếm tỷ lệ khá nhiều trong điều kiện Việt Nam hiện nay. Mặc dù vậy, so sánh với các nghiên cứu về điều trị UTDD nói chung thì kết quả của nghiên cứu này đã cải thiện rõ rệt. Nhất là với những nghiên cứu phẫu thuật đơn thuân trên nhóm bênh nhân thuộc nhiều giai đoạn và mức độ xâm lấn u. So sánh với các nghiên cứu về hóa trị bổ trợ gân đây trên các bệnh nhân có yếu tố nguy cơ thấp hơn thì kết quả của nghiên cứu này với các bệnh nhân có yếu tố nguy cơ cao hơn cũng cho thấy những bước tiến tích cực.

Thông thường trong nhiều bệnh lý ung thư thì tuổi cao là yếu tố bất lợi. Tuổi càng cao thì nguy cơ mắc các bệnh kèm theo tăng nên nguy cơ tử vong tăng lên. Ngoài ra tỉ lệ mắc bệnh gặp nhiêu ở nam giới, tuy nhiên kết quả nghiên cứu chưa tìm thây mối liên quan giữa thời gian sống thêm theo tuổi và giới tính.

Về kích thước u, chưa tìm thấy sự khác biêtt có ý nghĩa thống kê về thời gian sống thêm giữa 2 nhóm kích thước u trên và dưới $3 \mathrm{~cm}$. Nguyên do là nghiên cứu tập trung nhóm có u xâm lấn tới hoăcc qua thanh mạc. Một số bênh nhân mặc dù kích thước u không lớn nhưng đã xâm lấn sâu nên sự khác biệt là không lớn. Tiên lượng sônng chủ yểu phụ thuốc mức độ xâm lấn u. So sánh với các nghiên cứu đánh giá tâp trung trên nhóm bệnh nhân có u đã xâm lấn bề mặt thanh mạc hoặc cấu trúc lân cận như của Fukada (2011) thì 
kích thước u không phải là yếu tố liên quan tới sống thêm [6].

Giai đoạn bệnh là yếu tố tiên lượng quan trọng ảnh hưởng đến thời gian sống thêm sau mổ. Tuy nhiên chúng tôi chưa thấy mối liên quan giữa thời gian sống thêm và giai đoạn bệnh. Điêu này có thể là do cỡ mẫu nghiên cứu còn nhỏ.

Bênh nhân có bênh tim mach kèm theo có thời gian sống thêm trung bình là $37,45 \pm 3,5$ tháng thấp hơn so với thời gian sống thêm trung bình của nhóm không có bênh tim mach kèm theo $(51,8 \pm 1,8$ tháng). Sư khác biêt có ý nghĩa thống kê với $p<0,05$. Do bệnh nhân bệnh lý tim mạch thường phục hồi sau mổ chậm hơn, ảnh hưởng đến liều và liệu trình điều trị hóa chất bổ trợ sau mổ

\section{KẾT LUÂN}

Hóa trị bổ trợ phác đồ EOX đem lại lợi ích sống thêm trên bệnh nhân cao tuổi ung thư dạ dày đã phẫu thuật triệt căn có nguy cơ cao với tỳ lệ sống thêm toàn bộ ước tính theo Kaplan Meier sau 3 năm, 4 năm và 5 năm tương ứng là $85,6 \%, 59,7 \%$, 46,7\%, tỷ lệ sống thêm không bệnh sau 3 năm, 4 năm và 5 năm ước tính tương ứng là $63,5 \%, 45,8 \%$ và $35,6 \%$.

\section{TÀI LIÊU THAM KHẢO}

1. World Health Organization (2018). Gastric Cancer. International Agency for Research on Cancer, GLOBOCAN 2018.

2. Vũ Hải (2009), Nghiên cứu chỉ đinh các phương pháp phâu thuật, hoá chất bổ trợ và đánh giá kêt quả điêu trị ung thư da dày tai Bệnh viện K, Luận án Tiến sĩ y học, Học viện Quẩn y.

3. Phan Cảnh Duy (2019), "Kết quả điêu trị ung thư biểu mô tuyến da day phân xa da dày giai đoạn tiến triển tại chố bằng phấu thuật kết hợp xạ - hóa sau mổ", Tap chí Y họ lâm sàng, Bênh viện Trung Ương Huể, số 55, tr: $80-88$.

4. Vũ Quang Toản, Đoàn Hữu Nghi, Đỗ Anh Tú (2015), Điều trị ung thư dạ dày tiên triển tại chô bằng phẫu thuật và hóa trị bổ trợ EOX, Tạp chí Y hoc lâm sàng, số 29/2015, 270-278.

5. Bang Y.-J., Kim Y.-W., Yang H.-K. et al (2012). Adjuvant capecitabine and oxaliplatin for gastric cancer after D2 gastrectomy (CLASSIC): a phase 3 open-label, randomised controlled trial. The Lancet, 379(9813), 315-321.

6. Fukuda N., Sugiyama Y., Wada J. (2011). Prognostic factors of T4 gastric cancer patients undergoing potentially curative resection. World journal of gastroenterology: WJG, 17(9), 1180.

\section{CÁC YẾU TỐ LIÊN QUAN ĐẾN TÁI PHÁT MUỘN SAU ĐộT QUỴ THIẾU MÁU NÃO CẤP TẠI TIỀN GIANG}

\section{TÓM TẮT}

Mở đâu: Nguy cơ tái phát muộn sau đột quy thiếu máu não cấp thì vẫn còn cao mặc dù đã có những cải thiện trong chiến lược phòng ngữa đột quy thứ phát. Việc xác định tỉ suất tái phát đột quy muộn và các yễu tố liên quan đến nguy cơ tái phát đột quy muộn vẫn còn han chế. Muc tiêu nghiên cứu: Xác đinh tỷ suất tái phát đột quỵ tích lũy tại thời điểm 1 năm và các yếu tố liên quan độc lập đến tái phát muôn sau đột quy thiếu máu não cấp. Phương pháp nghiên cứu: Nghiên cứu đoàn hê quan sát, tiền cứu. Sử dung ước tính Kaplan-Meier và mô hình hồi quy Cox để xác định tỷ suất tái phát đột quy tích lũy và các yếu tố liên quan độc lập đến nguy cơ tái phát muộn sau đột quy. thiếu máu não cuc bô cấp. Kết quả: Trong 2 năm, chúng tôi thu thập được 520 bệnh nhân đột quỵ thiếu máu não cục bộ cấp và theo dõi 1 năm. Tỷ suất tái phát đột quỵ tích lũy tại thời điểm 1 năm là $21,2 \%$.

\footnotetext{
*Bệnh viện Đa khoa Trung tâm Tiền Giang

**Đai hoc Y dước Thành phố Hồ Chí Minh.

Chịu trách nhiệm chính: Nguyễn Văn Dũng

Email: dungbvtg@gmail.com

Ngày nhận bài: 12.3.2021

Ngày phản biên khoa hoc: 11.5.2021

Ngày duyệt bài: 17.5.2021
}

\section{Nguyễn Văn Dũng*, Cao Phi Phong**}

Các yếu tố liên quan độc lập với đột quy tái phát bao gồm trình độ học vấn, tiền sử đột quy./TIA, tiền sử nhồi máu cơ tim, rung nhĩ, lấp mạch tứ tim và dùng thuốc statin. Kết luân: Tỷ suất tái phát đôt quy tích lũy tai thời điểm 1 năm là 21,2\%. Các yếu tố liên quan đốc lập với đột quy tái phát là trình độ học vấn, tiền sử đột quy./TIA, tiền sử nhồi máu cơ tim, rung nhĩ, lấp mach từ tim và dùng thuốc statin.

Tư khóa: yếu tố, tái phát muộn, liên quan, đột quỵ thiếu máu não cấp.

\section{SUMMARY \\ FACTORS ASSOCIATED WITH LATE RECURRENCE AFTER ACUTE ISCHEMIC STROKE IN TIEN GIANG}

Background: The risk of late recurrence after acute ischemic stroke remains high despite improvements in secondary stroke prevention strategies. The determination of late stroke recurrence rate and factors associated with to late stroke recurrence is still limited. Objectives: Determine the cumulative stroke recurrence rate at 1 year and factors independently associated with to the risk of late recurrence after acute ischemic stroke. Methods: Prospective, observational cohort study. Using KaplanMeier estimation and Cox regression model to determine the cumulative stroke recurrence rate and 